\title{
Editorial
}

\section{An end to income tax?}

\author{
Barry Bracewell-Milnes, Banstead, United Kingdom
}

The tax burden has risen substantially over the last generation throughout the industrialised West. Total tax revenue as a percentage of gross domestic product was an unweighted average of 26.6 per cent for the twenty-three countries of the OECD in 1965 (the first year for which the OECD published this figure) and 38.8 per cent in 1987 , a rise of nearly a half. No country moved against this trend.

There are two main reasons for this consistent pattern. The first is tax buoyancy (Intertax editorial, April 1990): in the absence of countervailing measures, tax revenue rises faster than GDP in most OECD countries, if not all, and many governments have their own reasons for not taking countervailing measures. The second reason is institutional: the Public Choice school of economists (such as Buchanan and Tullock) has explained why in democratic societies particular lobbies and interests (including those of Government Ministers and officials in their private capacities) tend to prevail over the general interest: the interest in tax reduction is general, the interests in various forms of additional government spending are particular.

Some people welcome this unremitting pressure for increased government spending and taxation; others regard an increase in the tax burden as undesirable but unavoidable and a reduction as desirable but unattainable. And there is good reason to expect a further massive increase in the tax burden over the next generation in the absence of a programme for preventing this outcome.

The alternative is to use the proceeds of tax buoyancy to reduce rates of tax year by year. A radical long-term programme of reductions in tax rates is compatible with the maintenance of existing levels of government spending, or even with an increase in these levels, provided only that the growth of government spending is less than the buoyancy of tax revenue in the absence of cuts in tax rates. And government spending could well increase less rapidly than GDP: as people grow more prosperous, they have more opportunity to provide for themselves welfare services at present provided free-at-the-point-of-consumption by the State.

The Institute of Directors, London, has recently published a programme applying these principles to the abolition of taxes on income and capital over the next fifteen to twenty-five years or even longer. (Continuing Tax Reform: A Long-term Strategy for Government Spending and Taxation, Director Publications, London, £15.) The desirability of this programme is by no means universally accepted. But the strategy is realistic and internally consistent and deserves recognition as one of the available options - an option which will effectively be foreclosed if policy is entirely determined by short-term considerations and pressures.

If it is feasible to abolish income tax over the next generation, or at least to reduce it drastically, a number of tax reforms that attract interest at present become correspondingly less important. In particular, pension provision, life assurance and the financing of house purchase through mortgage may have timescales of thirty years or more: there is little point in disturbing the present tax regimes for these transactions if the income taxes on which they are based may be drastically reduced or even abolished over a shorter period. 